\title{
Demand Response and Ancillary Service Management Using Fractional-Order Integral Indicator and Dynamic Game Model for an Aggregator Program in Smart Grids
}

\author{
Long-Yi Chang ${ }^{1,2}$ • Yi-Nung Chung ${ }^{1}$ - Shi-Jaw Chen ${ }^{3}$ Chao-Lin Kuo ${ }^{4}$. \\ Chia-Hung Lin $^{5}$
}

Received: 30 June 2016 / Accepted: 4 October 2016 / Published online: 18 November 2016

(c) Springer Science+Business Media Singapore 2016

\begin{abstract}
To avoid penalties on over-contract demand, electricity customers can adopt a demand response strategy to shift or reduce demands from main grid during peak periods or partial peak periods. The direct or indirect load control is a common strategy used to change operational conditions
\end{abstract}

Yi-Nung Chung

ynchung@cc.ncue.edu.tw

Chia-Hung Lin

eech153@gmail.com

Long-Yi Chang

lychang@mail.ncut.edu.tw

Shi-Jaw Chen

shijaw.chen@gmail.com

Chao-Lin Kuo

clkuo@mail.nkmu.edu.tw

1 Department of Electrical Engineering, National Changhua University of Education, Changhua City 50074, Taiwan

2 Department of Electrical Engineering, National Chin-Yi University of Technology, Taiping District, Taichung City, 41170, Taiwan

3 Department of Greenergy Science and Technology, Kao-Yuan University, Lu-Chu District, Kaohsiung City, 82151, Taiwan

4 Department of Maritime Information and Technology, National Kaohsiung Marine University, Cijin District, Kaohsiung City, 80543, Taiwan

5 Department of Electrical Engineering, Kao-Yuan University, Lu-Chu District, Kaohsiung City, 82151, Taiwan with or without incentive / contractual strategies. The timeof-use and real-time pricing in addition to incentive services can encourage customers to change their preferences, further reducing demands during contractual periods. Therefore, ancillary services can manage and dispatch ancillary power, such as renewable energy, stored energy, and onsite generation, to reduce expensive power generation from main grid and to meet the customers' extra demands in smart grids. The fractional-order integral operation is used to calculate the area under the curve for evaluating power consumption at a scheduled timing interval of $15 \mathrm{~min} / 1$ hour and identify demand levels. The dynamic game model is employed to dispatch the available distributed generations to meet the customers' extra demands. For an aggregator program, results will show that the proposed method can reduce the demand from the main grid and increase system flexibility to activate the active-duty distributed generations. Benefits for billing charges may arise.

Keywords Demand response - Distributed generation · Fractional-order integral $\cdot$ Area under the curve $\cdot$ Dynamic game model

\section{Introduction}

Demand response is a management strategy employed to make changes in customer usages and coordinates with power utilities or electricity market conditions. Its strategy allows the consumptions to reduce by direct load controls (DLCs), indirect load controls (ILCs), or incentive controls $[1,2]$. In a DLC strategy, utilities directly send command signals to switch off the lower priority loads. 
An ILC strategy, including incentive and contractual controls, uses incentive payments to reduce customer demands. Hence, customers can obtain pricing information to control power consumption, such as time-of-use (TOU), real-time (RT), and peak time prices. These conventional methods are performed by power utilities and independent system operators, which can reduce peak period (PP) demands or shift demands to the off-peak period (OPP). In this operating scheme, lower priority loads need to switch off, and distributed generations (DGs), such as photovoltaic energy and wind power, are not fully utilized to meet the local demands. In an innovative electricity market model, an aggregator business model integrates a demand response aggregator and a generation aggregator into a single purchasing unit with DG pools [3], as seen in Fig. 1. This model offers demand responses and ancillary services provide available incentives to use the DG resources. This leads to reduce high energy costs, high-carbon power generation, and transmission loss. In addition, a generation aggregator meets the demands to satisfy the electricity customers [4, 5], and dispatches available power for customers or integrates the exported electricity. Hence, DG pools as a virtual power plant (VPP) can also reduce demands from the main grid, such as small scaled power plant $(<150 \mathrm{~kW})$, rooftop photovoltaic system, and small-scaled wind farm. The VPP provides power supply to alleviate the extra power demands in PP hours, and provides back-up powers while uncertain outage event occurrences [6, 7]. A virtual net metering (VNM) network [8, 9] can monitor DG information to dispatch available powers for onsite customers or exports rest to other customers and power utility.

The ancillary power capacity should be at least $50 \%$ of the maximum demands. A VPP is employed to supply backup power during peak load and to avoid the load shedding. Onsite generations, such as Eq. 1 renewable energy and stored energy, and Eq. 2 AC generators: microgenerators, small scaled co-generation systems, and diesel-generators [10-12], can be employed temporarily instead of using electricity from the main grid during peak demand, and renewable energy can synchronously store into the storage devices by using power converters (DC-DC or AC-DC) $[11,13,14]$. Droop controllers regulate the voltage and frequency at the connection point of common coupling (PCC) [7] by using power inverters. To activate DG resources, onsite generations are employed to support net changes in smart grids [11, 15, 16]. Advanced metering / grid infrastructure (AMI/AGI) and VNM [8, 9, 17, 18] provide a smart grid platform to perform the consumption modifications and to dispatch the available DGs with smart meters, bidirectional communication, intelligent computations and controls to achieve the demand response and ancillary service tasks [19]. In this electricity market, an aggregator program acts as a mediator between end users and power utilities to (1) perform the demand response during PP or contractual hours, (2) activate the available DGs for PP demands, (3) promote energy and load managements, and (4) avoid exceeding the contract demands.

Based on day-ahead or hour-ahead scheduling [20, 21], the capacity of demand responses and the customer load profile can be predicted, while electricity prices, active power, and reactive power can also be determined. In this situation, AMI / AGI can monitor the load profiles, voltages, and currents, while the customers' consumptions can be monitored in the timing sector from $15 \mathrm{~min}$ to 1 hour. VNM can monitor the exported electricity generation within its local load area and resell it to nearby customers. However, extra electricity demands, such as air conditioners and refrigerators, might cause over the contractual demands in summer season. A better strategy can reduce the electricity bills for unpredicted demand variations. In addition, an aggregator should also provide sustainable ancillary power to reduce the risk for outage event occurrences. According to forecasting demand and DG information, the energy management offers available DGs and achieves adequate electricity compensations. Therefore, this study proposes a management strategy to reduce peak demand from the main grid and reduce retail energy costs. The fractionalorder integral (FOI) based indicator is designed as an index
Fig. 1 An aggregator program includes demand response and ancillary service in an electricity market

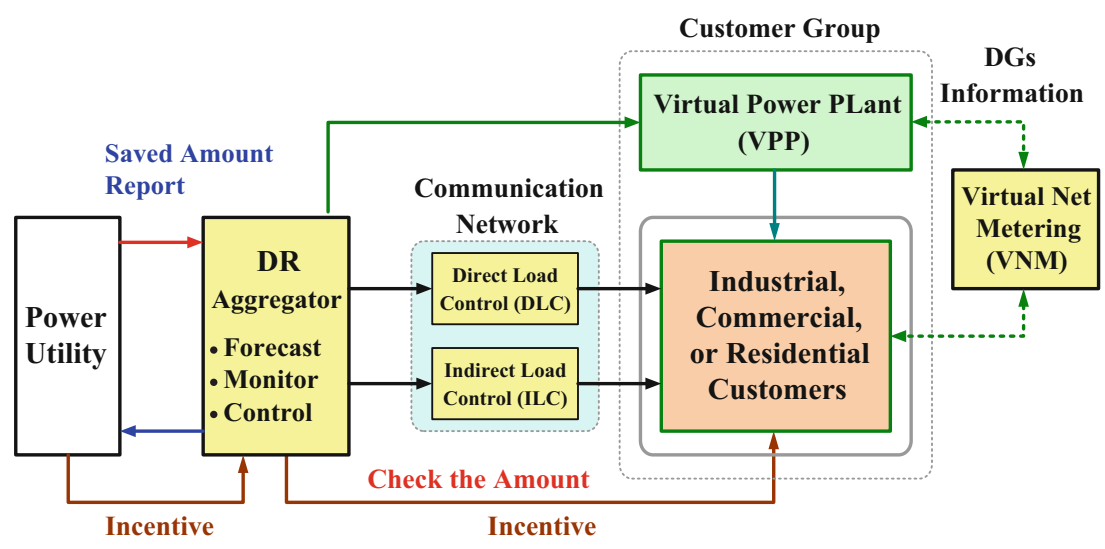


to determine the ratio of customer demand and contractual demand. Discrete FOI computation [22-24] is used to calculate the area under the curve (AUC) at each 15-min or 1-h time interval. The AUC ratio (AUCR) is carried out to identify the changes in customer demand, including the ranges within $\pm 10 \%$ of contractual demand and over $10 \%$ contractual demand. The AUCR index is employed to determine the constraints of the demand, referring to the threshold values, $<0.90,0.90^{\sim} 1.10$, and $>1.10$. Electricity customers can be incentive to reduce demand from the main grid through dynamic electricity prices, while the DG resources are available during the PP or partial peak period (PPP). Then, the proposed dynamic game model (DGM) $[25,26]$ is carried out to dispatch the onsite DG resources for meeting the customers' extra demands or incentive demand response. The flexibility strategy is given a contract duration to balance supply and demand in time, with the aim to (1) restrain PP demands, (2) reduce highprice demand from the main grid, (3) to avoid exceeding the contract demands, and (4) to activate the active-duty DGs. For the proposed integrating AUCR indicator with FOI and DGM, energy managements and ancillary services can be achieved for an aggregator program in smart grids.

The remainder of this paper is organized as follows: "Demand Response Strategy" describes the demand response strategy in microdistribution systems, "Methodology" addresses the methodology involved in this study, and "Simulation Results" and "Conclusion" present simulation results and conclusions to demonstrate the efficiency of the proposed model.

\section{Demand Response Strategy}

Based on advanced controls and dynamic managements, DGs can both reduce power losses and improve higher energy efficiency, as shown in Fig. 2. For electricity customers, a capacity based demand response can reduce payments in a peak period under contractual demand. For power utilities, DGs can reduce the requirement of expensive power plants and electricity facilities in meeting peak demands. In addition, depending on contractual demand, electricity customers can obtain credit on their billing charges. After determining the contractual demands, the demand response strategy may include [27-29]:

- reserve capacity (>50\% of the maximum demands): renewable energy and ac generators provide for electricity consumption during critical peak or peak demands.

- storage capacity: battery banks store renewable energy during OPP hours and provide electricity consumption during critical peak or peak demands,

To achieve demand response, active information management provides two-way communication to and from power utilities, such as pricing, billing charges, predicted demands for day-ahead / hour-ahead scheduling [20, 21], and reserve capacity can be sold back to the grid for time-of-day scheduling. VNM network provides DG information and allows customers in a residential, commercial, or industrial multitenant group to participate in a common renewable source, such as solar energy or wind energy
Fig. 2 The concept of peak-period dynamic demand from the distributed generations

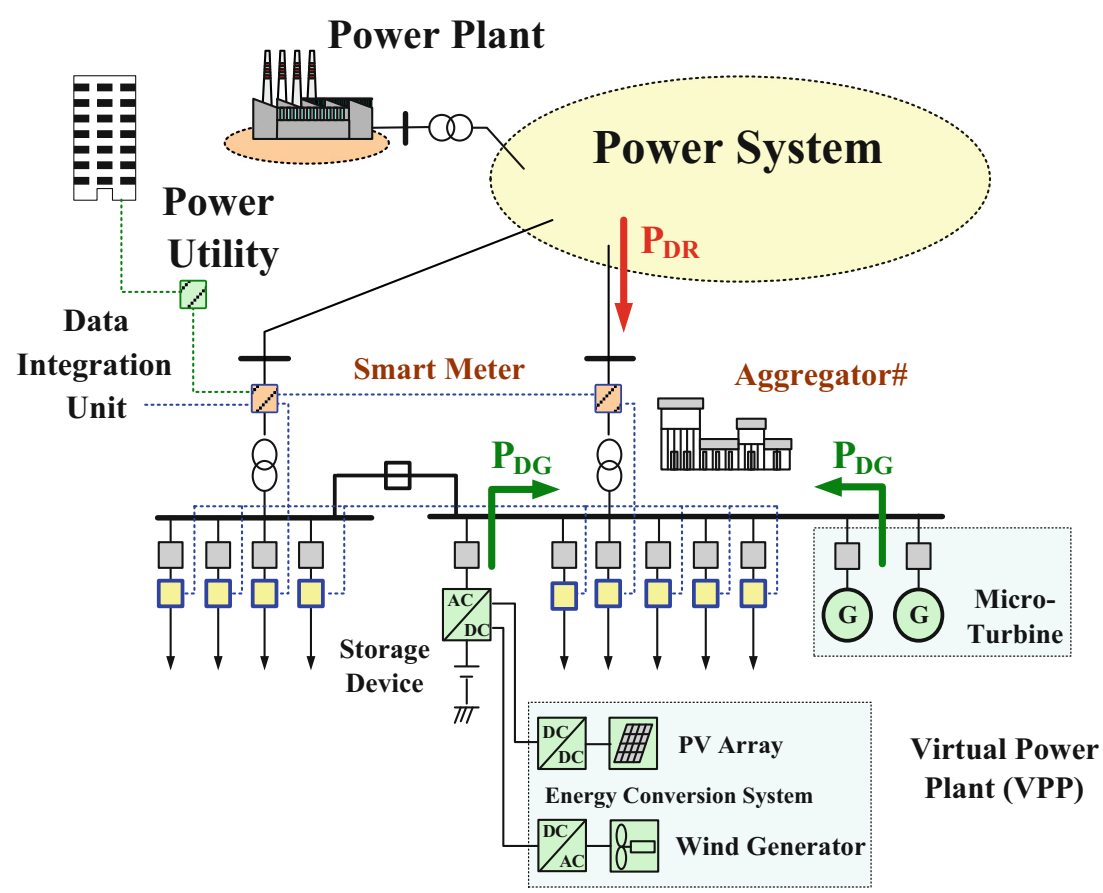


system. An AMI consists of smart meters, a data integration unit, computers, and the use of telecommunication / power line carrier techniques, as seen in Fig. 2, which can provide predicted usage profiles, daily usage profiles, and real time usage data. Electricity customers then have smart meters to track power consumption with options to change the measuring frequency from 15 to 60 minutes, using the following functions:

- monitor the usage of load profiles, voltage, and current,

- detect the abnormality electricity consumption or service without a billing charge,

- detect outages and verify online restoration.

Ensuring reliability, quality, and continuity of service is an important issue in a smart-grid environment. The AMI can provide available information for electricity customers and system operators. In this innovative electricity market, demand response aggregators join a group of customers and pool DG resources, while forecast loads and DG capacity to meet the demand. By combining the FOI based AUCR indicator and the DGM, the aim of proposed model is to reduce desired demands from the main grid. Hence, high-priced power demand can be reduced. DG resources can fully utilize to meet the customer demands, and also resell power to the power utility or other customers.

\section{Methodology}

\section{Customer Monthly Charges}

In Taiwan, an electricity customer determines contractual demand for a specified capacity, $\geq 50 \mathrm{~kW}$, and three-phase rated low level voltages, $220 \mathrm{~V} / 380 \mathrm{~V}$, sufficient to meet normal maximum demand. Customers use less than contractual demands they will be charged the contract requirements $(\$ / \mathrm{kW})$. If any reading of the demand meter in any month exceeds the contractual demand, the maximum reading becomes the new contractual demand. The customer monthly charge covers the cost of electricity equipment, maintenance expenses, and generation of fuel costs, including the seasonal rate (SR), non SR, TOU rate, and non TOU rate. For example, the SR is from 1 June to 30 September (in summer) per year, and the peak periods are from 10:00 12:00a.m. and 13:00-17:00p.m. daily, as seen in Fig. 3. Thus, the monthly charges for SR are divided into the base charge, $C_{b}$, and the penalty, $C_{p}$, and are defined as

$C_{b}=S_{p p} \times M_{p p}+S_{p p p} \times M_{p p p}+S_{o p p} \times M_{o p p}$

where $S_{p p}, S_{p p p}$, and $S_{o p p}$ are the contractual demands $(\mathrm{kW})$ at peak period (PP), partial peak period (PPP), and off-
Fig. 3 Billing charges for contract demand in Taiwan. a Contract demand schedule, $\mathbf{b}$ TOU rate and non TOU rate schedule (capacity $\geq 50 \mathrm{KW}$, three-phase rated voltage levels, 220V/380V) (a)

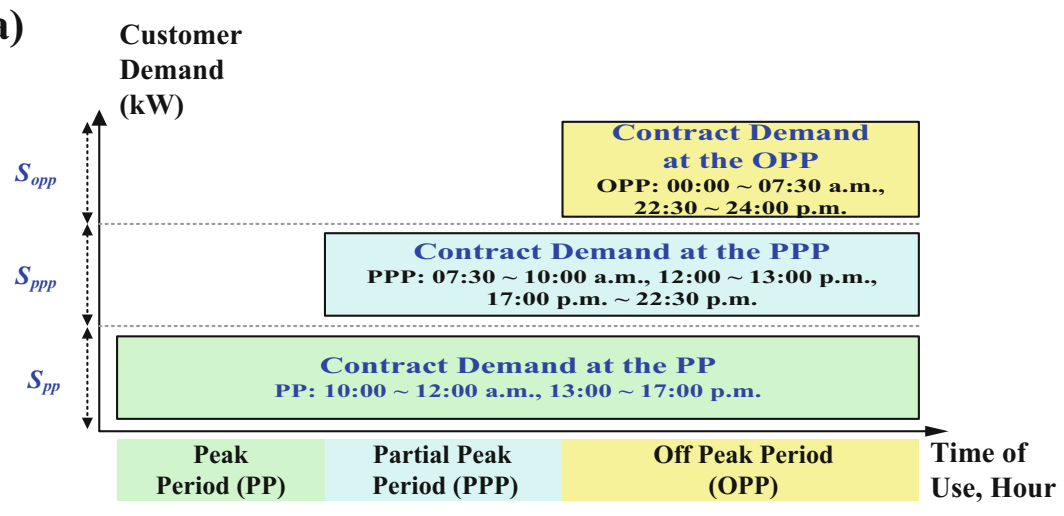

(b)
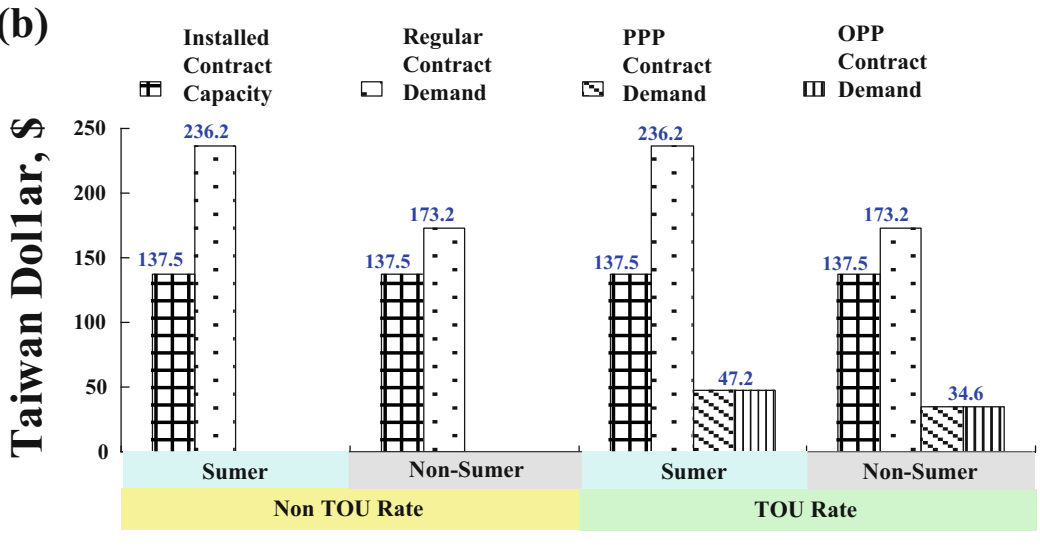
peak period (OPP) hours, respectively, as seen in Fig. 3a; and parameters, $M_{p p}, M_{p p p}$, and $M_{o p p}$ are the TOU rates $(\$ / \mathrm{kW})$ at the three time periods, as seen in Fig. 3b. In addition, the demand charge of the excess within $10 \%$ of the contractual demand is charged at twice the rate of the con- tractual demand, and the excess over $10 \%$ of the contractual demand is charged at three times the rate. For TOU rates, the penalty in the three periods is defined as

(a) PP hours

$$
\begin{aligned}
\Delta S_{p p} & =S_{m}-S_{p p}, \Delta S_{p p}>0 \\
C_{p, p p} & =\left\{\begin{array}{l}
0, \Delta S_{p p} \leq 0 \\
2 \times M_{p p} \times \Delta S_{p p}, 0<\Delta S_{p p} \leq 0.1 \times S_{p p} \\
M_{p p} \times\left(3 \times \Delta S_{p p}-0.1 \times S_{p p}\right), \Delta S_{p p}>0.1 \times S_{p p}
\end{array}\right.
\end{aligned}
$$

where $S_{m}$ is the metering maximum demand $(\mathrm{kW})$; $\Delta S_{p p}$ is the difference $(\mathrm{kW})$ in PP, while $\Delta S_{p p}>0$ is the over the contractual demand; $M_{p p}$ is the TOU rates at PP hours, where $M_{p p}=236.2(\$ / \mathrm{kW})$ for summer season and $M_{p p}=173.2(\$ / \mathrm{kW})$ for non-summer season. Figure $3 b$ shows the power service's billing charges and rates $(\$ / \mathrm{kW})$ for contractual demands in Taiwan, including the non-TOU rate and the TOU rate.

(b) PPP hours:

$$
\begin{aligned}
\Delta S_{p p p} & =S_{m}-\left(S_{p p}+S_{p p p}\right) \\
C_{p, p p p} & =\left\{\begin{array}{l}
0, \Delta S_{p p p}<\Delta S_{p p} \\
1.15 \times M_{p p p} \times\left(\Delta S_{p p p}-\Delta S_{p p}\right),\left(\Delta S_{p p p}-\Delta S_{p p}\right) \leq 0.1 \times S_{p p p} \\
M_{p p p} \times\left[3 \times\left(\Delta S_{p p p}-\Delta S_{p p}\right)-0.1 \times S_{p p p}\right] \times 1.15,\left(\Delta S_{p p p}-\Delta S_{p p}\right)>0.1 \times S_{p p p}
\end{array}\right.
\end{aligned}
$$

where $\Delta S_{p p p}$ is the difference $(\mathrm{kW})$ in PPP; $M_{p p p}$ is the TOU rates at PPP hours, where $M_{p p p}=47.2$ $(\$ / \mathrm{kW})$ for summer season and $M_{p p p}=34.6(\$ / \mathrm{kW})$ for non-summer season.

(c) OPP hours:

$$
\begin{aligned}
\Delta S_{o p p} & =S_{m}-\left(S_{p p}+S_{p p p}+S_{o p p}\right) \\
C_{p, o p p} & =\left\{\begin{array}{l}
0, \Delta S_{o p p}<\left(\Delta S_{p p}+\Delta S_{p p p}\right) \\
2 \times M_{o p p} \times\left[\Delta S_{o p p}-\left(\Delta S_{p p}+\Delta S_{p p p}\right)\right] \times 1.15, \Delta S_{o p p}-\left(\Delta S_{p p}+\Delta S_{p p p}\right) \leq 0.1 \times S_{o p p} \\
M_{o p p} \times\left\{3 \times\left[\Delta S_{o p p}-\left(\Delta S_{p p}+\Delta S_{p p p}\right)\right]-0.1 \times S_{o p p}\right\} \times 1.15, \Delta S_{o p p}-\left(\Delta S_{p p}+\Delta S_{p p p}\right)>0.1 \times S_{o p p}
\end{array}\right.
\end{aligned}
$$

where $\Delta S_{o p p}$ is the difference $(\mathrm{kW})$ in OPP; $M_{o p p}$ is the TOU rates at OPP hours, where $M_{o p p}=47.2$ $(\$ / \mathrm{kW})$ for summer season and $M_{o p p}=34.6(\$ / \mathrm{kW})$ for non-summer season.
In addition, the power factor (PF) is used to indicate the efficiency level of electrical usage. An electric rate also includes surcharges, while the customer has $\mathrm{PF}$ less than the threshold value, $80 \%$. Surcharge and reward, $C_{S}$, are defined as

$$
\begin{aligned}
P F & =\frac{k W H}{\sqrt{k W H^{2}+k V A R H^{2}}} \times 100 \% \geq 80 \% \\
C_{S} & =\left\{\begin{array}{l}
C_{S, S}, P F<80 \% \\
C_{S, R}, P F \geq 80 \%
\end{array}=\left\{\begin{array}{l}
C_{b} \times 0.003 \times(0.8-P F), P F<80 \% \\
C_{b} \times 0.015 \times(0.8-P F), P F \geq 80 \%
\end{array}\right.\right.
\end{aligned}
$$

where $C_{b}$ is the base charge for TOU rate; $\mathrm{PF}=80 \%$ is the threshold value, while $\mathrm{PF}<80 \%$, surcharge, $S_{S, S}$, can be computed, otherwise, electricity customers will obtain the reward, $S_{\mathbf{S}, \mathbf{R}}$. The monthly charge amount for contract demand is

$$
C=C_{b}+C_{S}
$$

\section{Discrete Fractional Order Integral (FOI)}

Fractional-order differentiation and integration were conducted using fractional calculus with non-integer orders; when operations are conducted with integer order, "value change per time" or "AUC" can be obtained [24, 30]. Fractional-order calculus was employed to describe 
dynamic behaviors in both time and frequency domains. For signal processing, the FOI employs all non-integer numbers to deal with signals, and the summation is computed using ratios of the Gamma function, $\Gamma(\alpha)$, incorporating the number of sampling data points in the range $\left[t_{0}, t_{1}\right]$, and the fractional-order parameters, $\alpha$. Parameters, $\alpha$ and $t$, are the limits of operation. The original continuous FOI, the $\alpha$ th FOI of function $P(t), 0<\alpha<1, \alpha \in R$, is given by [22]

$D^{-\alpha} P(t) \approx \frac{1}{\Gamma(\alpha)} \int_{t_{0}}^{t_{1}}(t-\tau)^{\alpha-1} P(\tau) d \tau$

where numerical integration is computed using the Riemann sum over the variable $t$ at time step $\tau$. The two definitions, such as Riemann-Liouville (R-L) or Grünwald-Letnikov (G-L) fractional approximations, [22-24] are carried out as the basis for discrete formulations and computations, and were derived from the iterated derivative formula. Therefore, Eq. 11 can be represented as the discrete fractionalorder operator using the G-L definition as [22-24]

$D^{-\alpha} P(t) \approx \lim _{\Delta \tau \rightarrow 0}(\Delta \tau)^{\alpha} \sum_{i=0}^{n-1}\left|(-1)^{i}\left(\begin{array}{l}-\alpha \\ i\end{array}\right) P(t-i \cdot \Delta \tau)\right|$

where $0<\alpha<1$ for the FOI process, $\alpha \in R ;-1<\alpha<0$ for the fractional derivative process; integer, $\alpha=+1$, for integer-order differentiation; $\alpha$ as integer is the integerorder differentiation or integration process; $i=1,2,3$, $\ldots, n, n$ is the number of sampling points; and the binomial coefficients are given as

$\left(\begin{array}{l}\alpha \\ 0\end{array}\right)=1, \quad\left(\begin{array}{l}-\alpha \\ i\end{array}\right)=\left\{\begin{array}{l}1, i=0,-1<\alpha<0 \\ \frac{\Gamma(-\alpha-1)}{\Gamma(i+1) \Gamma(-\alpha-i+1)}, i>0\end{array}\right.$,

timing step for FOI process:

$\Delta \tau=\left(\frac{t_{1}-t_{0}}{n}\right)$

Time parameters, $t_{0}$ and $t_{1}$, are the limits of FOI at the time interval $\left[t_{0}, t_{1}\right]$. AUC is defined using integral computations as a positive area between the continuous function and the transverse-axis. In this study, we can compute the AUC of contractual demand, $P_{c d}[i]$, and the tracking energy consumption, $P_{t e c}[i]$, as shown in Fig. 4. The fractional-order AUCs during the tracking time are

$$
\begin{aligned}
& A U C_{c d} \approx \lim _{\Delta \tau \rightarrow 0}(\Delta \tau)^{\alpha} \sum_{i=0}^{n-1}\left|(-1)^{i}\left(\begin{array}{l}
-\alpha \\
i
\end{array}\right) P_{c d}[i]\right| \\
& A U C_{m e c} \approx \lim _{\Delta \tau \rightarrow 0}(\Delta \tau)^{\alpha} \sum_{i=0}^{n-1}\left|(-1)^{i}\left(\begin{array}{l}
-\alpha \\
i
\end{array}\right) P_{t e c}[i]\right|
\end{aligned}
$$

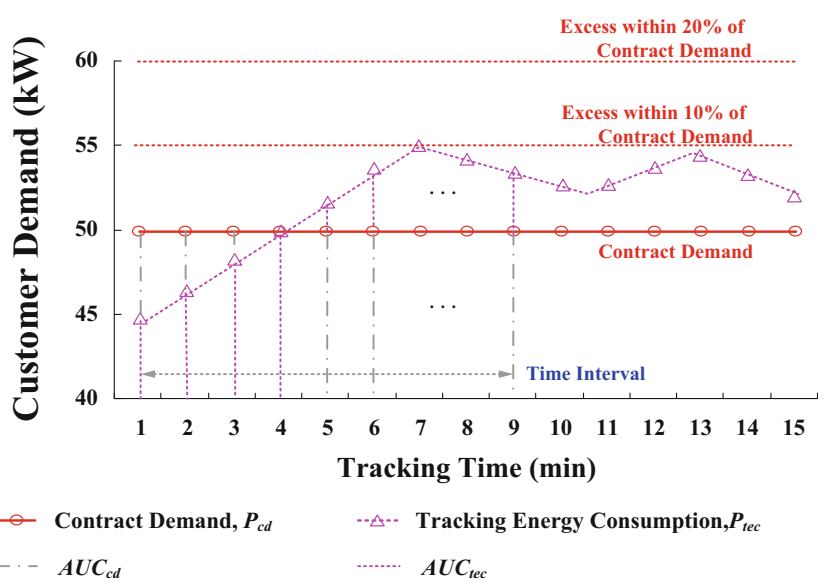

Fig. 4 Customer demand (kW) versus tracking time (min)

each tracking time:

$\Delta \tau=\left(\frac{15 \mathrm{~min}}{n}\right)$ or $\Delta \tau=\left(\frac{60 \mathrm{~min}}{n}\right)$

where the tracking energy consumption be obtained via metering measurement, referring to $P_{m e c}[i]$; the contractual demand is referred to as $P_{c d}[i], i \in[0, n-1]$. Therefore, the AUC ratio (AUCR) is defined as [28]

$A U C R=\frac{A U C_{m e c}}{A U C_{c d}}=\left\{\begin{array}{l}<0.90 \\ 0.90 \sim 1.10 \\ \geq 1.10\end{array}\right.$

where the AUCR should be less than 1.00 when the customer's demand is less than the contractual demand, as seen the white region in Fig. 5. In this study, we have three conditions for performing the demand response strategy, as follows:

- $A U C R<0.90$ (white region in Fig. 5) refers to $<90 \%$ of contractual demand: customer demand is less than the contractual demand, that is power consumption from the main grid and renewable energy,

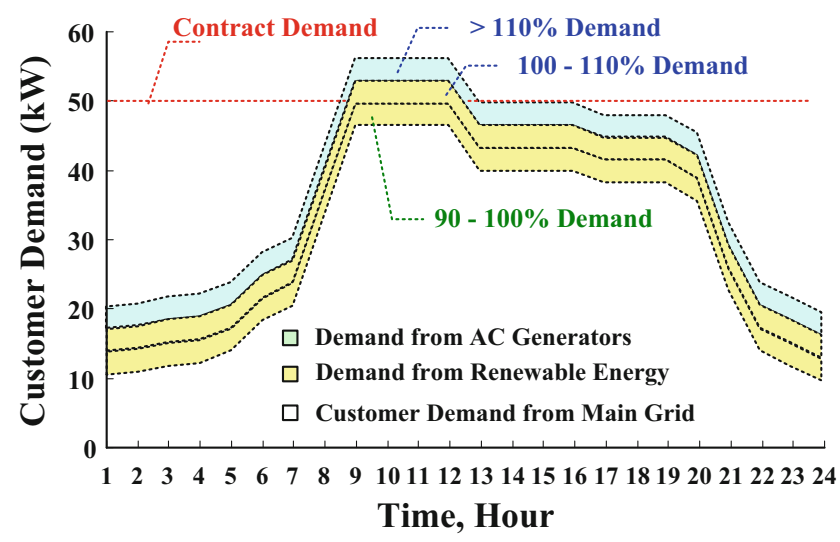

Fig. 5 Customer demand and ancillary capacities 
- $0.90 \leq A U C R<1.10$ (yellow region in Fig. 5) refers to $90 \% \sim 110 \%$ of contractual demand: customer demand approaches to the contractual demand $(-10 \%)$ or excesses within $+10 \%$ of the contract demand, while provides the extra demand using the renewable energy and storage units,

- $A U C R \geq 1.10$ (light blue region in Fig. 5) refers to $>110 \%$ of contractual demand: customer demand excesses over $10 \%$ of the contractual demand, while provides the extra demand using the ac generators, such as micro-generator and diesel-generator.

\section{Ancillary Power Sources' Dispatch}

Solar and wind generation systems produce renewable energy that can be synchronously stored into the storage devices on a microgrid. The charging percentage of a storage battery can be measured, a microcontroller can determine its supply loads, and its capacity can be $100 \%$ charged. In addition, AC generators are ancillary power sources integrated into a large power hybrid system to supply AC loads. These available ancillary power sources are installed near electricity customers and work to reduce power losses on transmission lines. Safety and reliable operations are important criteria, and the frequency and voltage must accommodate the loads required. All generators must respond in a coordinated manner to variable loads, and the frequency and voltage must be controlled to ensure the power balance in real time. A droop characteristic control performs the coordination of the generator with the frequency $(f)$ versus real power $(P)$ droop characteristic and the voltage $(V)$ versus reactive power $(Q)$ droop characteristic, to adjust demands for real and reactive power [7, 13, 14]. Depending on the loading conditions, they are selected to control the frequency within ranges of $\pm 0.5 \mathrm{~Hz}$ at a setting of $60 \mathrm{~Hz}$, with variations, $59.7-60.2 \mathrm{~Hz}$. At the connection PCC, the system frequency of the DBs can be determined so that real power is shared appropriately. The ancillary capacity can be $50 \%$ of the micro-distribution system's capacity, with a permissible $3 \%-5 \%$ voltage imbalance [11].

For each electricity customer, we have three operation conditions in the utility-connected mode and the ancillary power sources' dispatch as follows:

- $A U C R<0.90$ : customer demand is from both main grid and renewable energy; and adequate capacity is stored into the storage devices for local load balancing,

- $0.90 \leq A U C R<1.10$ : customer demand and extra demand are from main grid and renewable energy, and interconnects with storage units during the PP, PPP, or OPP hours and DG's outage,

- $\quad A U C R \geq 1.10$ : customer demand is also from main grid and renewable energy, and exceeding over $+10 \%$ of the contract demand is supplied by ac generators and other DGs at the local levels.

Different DGs offer various activation times or active-duty times, while DGs are available to serve in short-term operations. They are service for outage events occur or demand over expected values. Renewable energy usually relies on local weather conditions, with a typical forecast error of $5 \%-15 \%$ of installed capacity. The AC generators, such as a microgenerator and a diesel generator, have a stable ancillary capacity to supply PP demands with the specific contract. Figure 6 shows overall ancillary power source dispatch during PP, PPP, or OPP hours. The desired DG capacity, $S_{D G}$, is estimated by

$S_{D G, h} \approx\left\{\begin{array}{l}0.1 \times S_{\max }+S_{\text {Loss }}, A U C R_{h}<0.9 \\ 0.2 \times S_{\max }+S_{\text {Loss }}, 0.9 \leq A U C R_{h} \leq 1.1 \\ 0.3 \times S_{\max }+S_{\text {Loss }}, A U C R_{h}>1.1\end{array}\right.$

$S_{\text {Loss }} \leq 0.01 \times S_{\max }=0.01 \times\left(S_{p p}+S_{p p p}+S_{o p p}\right)$

where index, $h=1,2, \ldots, 96$, is the timing slot (15min slot in this study); PP durations are from 10:00 a.m. to 12:00 a.m. and 13:00 p.m. to 17:00 p.m. daily, PPP duration from 07:30 a.m. to 10:00 a.m., 12:00 p.m. to 13:00 p.m., and 17:00 p.m. to 22:30 p.m. daily, and OPP are the rest of durations. The dispatches of these ancillary power sources can be determined by the customer demands and capacities of the selected DG. Their quantities are parameterized with certainty factors (CFs) as shown in Figs. 7a and b, where the probability value is between " 0 " and " 1 " for presenting possible operation states, as follows

- for customer demand:

$$
\begin{aligned}
C F_{1, h} & =\left\{\begin{array}{l}
1, A U C R_{h} \leq 0.90 \\
\exp \left(-0.5 \times\left(\frac{A U C R_{h}-0.90}{0.10}\right)^{2}\right), A U C R_{h}>0.90
\end{array}\right. \\
C F_{2, h} & =\left\{\begin{array}{l}
1, A U C R_{h} \geq 1.00 \\
\exp \left(-0.5 \times\left(\frac{A U C R_{h}-1.00}{0.10}\right)^{2}\right), A U C R_{h}<1.00
\end{array}\right.
\end{aligned}
$$

- for desired DG's capacity:

$$
\begin{aligned}
& C F_{3, h}=\left\{\begin{array}{l}
1, S_{D G, h}<0.1 \times S_{\max } \\
\frac{S_{D G, h}}{0.1 \times S_{\max }}, S_{D G, h} \geq 0.1 \times S_{\max }
\end{array}, \quad S_{\max }=50 k W(23)\right. \\
& C F_{4, h}=\left\{\begin{array}{l}
0, S_{D G, h}<0.1 \times S_{\max } \\
\frac{S_{D G, h}}{0.1 \times S_{\max }}-1,0.1 \times S_{\max } \leq S_{D G, h}<0.2 \times S_{\max } \\
1, S_{D G, h} \geq 0.2 \times S_{\max }
\end{array}\right.
\end{aligned}
$$

We have four dispatch strategies in a DGM [25, 26, 29]; these are described in a strategic form in Table 1, with rows representing the operational states of the capacity of selected DGs and columns representing customer demand. Four operational states have strategy combinations, $\left(C F_{1, h}, C F_{3, h}\right),\left(C F_{2, h}, C F_{3, h}\right),\left(C F_{1, h}\right.$, 
Fig. 6 Ancillary power sources' dispatch

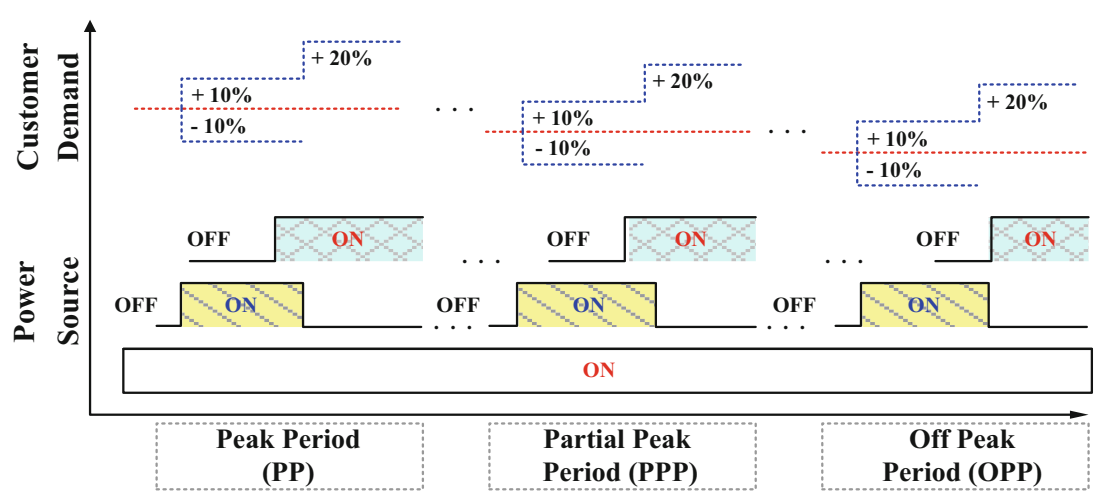

Demand from AC Generators

Demand from Renewable Energy

Customer Demand from Main Grid
$\left.C F_{4, h}\right)$, and $\left(C F_{2, h}, C F_{4, h}\right)$. Their states are independent if, and only if, their joint probabilities follow a multiplication rule. The outcomes of joint probabilities are given by

$S=\left[\begin{array}{ll}C F_{1, h} \times C F_{3, h} & C F_{2, h} \times C F_{3, h} \\ C F_{1, h} \times C F_{4, h} & C F_{2, h} \times C F_{4, h}\end{array}\right]=\left[\begin{array}{ll}s_{1, h} & s_{2, h} \\ s_{3, h} & s_{4, h}\end{array}\right]$

Hence, the dispatch of a selected DB can be determine as

$$
S^{+}=\max \left[\left(s_{1, h}+s_{3, h}\right),\left(s_{2, h}+s_{4, h}\right)\right]
$$

(a)
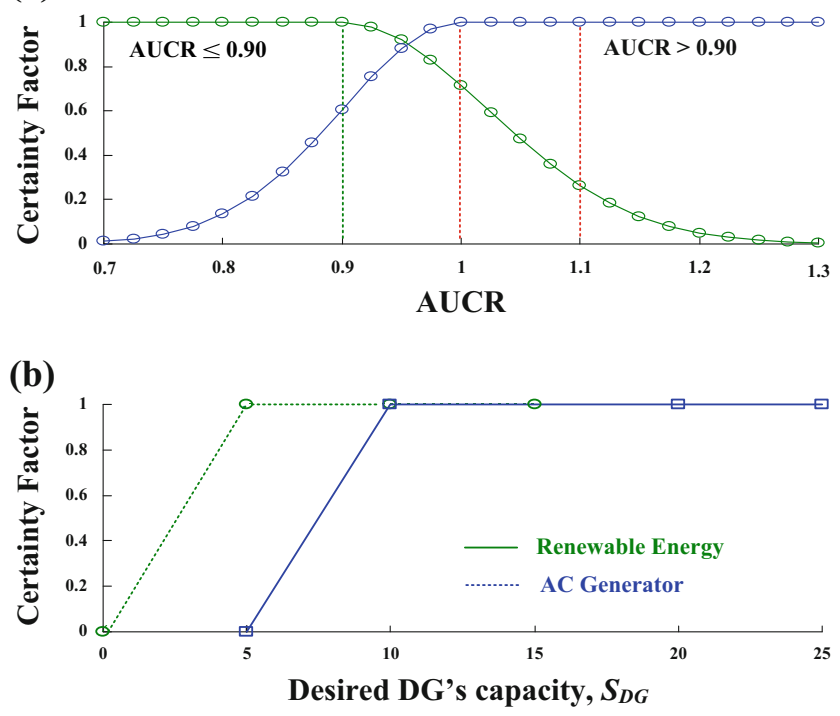

Fig. 7 Certainty factors for presenting the possible operation states. a Certainty factors versus AUCR index, b Certainty factors versus desired DG's capacities
- desired capacity of renewable energy, $S_{\text {renew }}$ :

$$
\begin{aligned}
& \left(s_{1, h}+s_{3, h}\right) \geq\left(s_{2, h}+s_{4, h}\right): \quad S_{\text {renew }}=S_{D G, h} \times\left(\frac{s_{1, h}}{s_{1, h}+s_{3, h}}\right) \\
& \text { or } \\
& \left(s_{1, h}+s_{3, h}\right) \leq\left(s_{2, h}+s_{4, h}\right): S_{\text {renew }}=S_{D G, h} \times\left(\frac{s_{2, h}}{s_{2, h}+s_{4, h}}\right)
\end{aligned}
$$

- desired capacity of ac generator, $S_{a c}$ :

$$
\begin{aligned}
& \left(s_{1, h}+s_{3, h}\right) \geq\left(s_{2, h}+s_{4, h}\right): \quad S_{a c}=S_{D G, h} \times\left(\frac{s_{3, h}}{s_{1, h}+s_{3, h}}\right) \\
& \text { or } \\
& \left(s_{1, h}+s_{3, h}\right) \leq\left(s_{2, h}+s_{4, h}\right): S_{a c}=S_{D G, h} \times\left(\frac{s_{4, h}}{s_{2, h}+s_{4, h}}\right)
\end{aligned}
$$

$\frac{1}{2} \times S_{a c, \max } \leq S_{a c} \leq S_{a c, \max }, \quad S_{\text {storage }} \leq 0.5 \times S_{\text {renew }}$

where $S_{a c}$, max is the maximum capacity of AC generators; and $S_{\text {renew }}$ and $S_{\text {storage }}$ represent solar energy and storage energy, respectively, during 08:00 and 17:00, otherwise for wind energy. At any time, an AC generator should be within its lower and upper rated capacities as Eq. 29. The start-up time depends on the size of the genset, but they can deliver electrical power loads from within 10 seconds to a few minutes after accelerating to the rated speed, warming-up, and synchronizing with the system. Thus, the desired capacity of renewable energy and $\mathrm{AC}$ generators can be determined using the Eqs. 27 and 28, respectively.

\section{Simulation Results}

A group of residential customers with a contract demand of $50 \mathrm{~kW}$, and a voltage level of $220 \mathrm{~V} / 380 \mathrm{~V}$, is conducted 
Table 1 Strategic form of dynamic game model

\begin{tabular}{lll}
\hline \multicolumn{1}{c}{ AUCR } & $\begin{array}{ll}A U C R<0.90, \\
C F_{1, h}\end{array}$ & $\begin{array}{l}\text { AUCR } \geq 0.90, \\
C F_{2, h}\end{array}$ \\
\hline Renewable Energy, $C F_{3, h}$ & $s_{1, h}=C F_{1, h} C F_{3, h}$ & $s_{2, h}=C F_{2, h} \times C F_{3, h}$ \\
AC Generator, $C F_{4, h}$ & $s_{3, h}=C F_{1, h} C F_{4, h}$ & $s_{4, h}=C F_{2, h} C F_{4, h}$ \\
Mixed Operation & $s_{1, h}+s_{3, h}$ & $s_{2, h}+s_{4, h}$ \\
\hline
\end{tabular}

to validate the proposed methods using practical load patterns (red line), as shown in Fig. 8a. Contract demands, $S_{p p}$, $S_{p p p}$, and $S_{o p p}$, at PP, PPP, and OPP time durations are $10 \mathrm{~kW}, 15 \mathrm{~kW}$, and $25 \mathrm{~kW}$, respectively. The three different time durations and TOU rates used in the summer are shown in Fig. 3. We consider ancillary power capacity to be at least $50 \%$ of the maximum contract demand. The DGs additionally have renewable energy and ac generators with $10-15 \mathrm{~kW}$ and $10 \mathrm{~kW}$ ancillary capacities and rated $5 \mathrm{~kW}$ of energy storage, respectively. We assume that the renewable energy is obtained from a small-scale wind farm (5 windturbine generators) and 15 photovoltaic (PV) panels, where each one has about rated power of $1 \mathrm{~kW}$, the DGs will be capable of reducing the peak demand by about $15 \mathrm{~kW}$. However, the efficiency of PV and wind energy conversions are influenced by environmental conditions such as solar radiation, temperature, wind speed, and weather conditions. A maximum power point tracking algorithm [17] is used to increase the conversion efficiency and account for environmental changes. Hence, an average rated capacity of $66 \%$ is estimated to be obtained from solar radiation and temperature that varies from $0.2 \mathrm{~kW} / \mathrm{m}^{2}$ to $1.0 \mathrm{~kW} / \mathrm{m}^{2}$ and from $25^{\circ} \mathrm{C}$ to $45^{\circ} \mathrm{C}$ in summer season, respectively. Wind speed ranges vary from $5 \mathrm{~m} / \mathrm{sec}$ to $10 \mathrm{~m} / \mathrm{sec}$ during the night or in the winter season.

The AC generators, including a micro-generator and a diesel-generator, have a stable ancillary capacity of $10 \mathrm{~kW}$ and can supply $10 \%$ of peak demand under specific contract levels. In addition, they have the capability to start-up and reach full load in about 15 minutes. Regular demands from the main grid allow $90 \%$ of day-ahead scheduled demands, while the remaining desired demands are obtained from the DGs, which reduce usages of permanent electricity provision by $10 \%$. Depending on contract demands, customers are promised credit on their billing charges, and the demand response needs to facilitate ancillary power for peak loads to avoid penalties from over-the-contract demand. The following procedures are used: (1) to identify the AUCR change at each time slot using fractional-order integrators; (2) determine the strategic operation combinations using the DGM; (3) to dispatch ancillary power.

Based on day-ahead scheduling, one day can be divided into 96 time slots; the forecasted demands in each time slot (15-min interval) are shown in Fig. 8a. Case study is made for a working day in a group of residential customers in a building, tariff ranges and demands have been addressed. To identify AUCR changes, fractional-order integrators, with $\alpha=0.10-0.20$, and sampling points $n=15$ (1-min tracking time), are employed to calculate AUCs using Eqs. 12 and 13. The overall AUCR can be seen to change, as shown in Fig. 8b, while their values exceed 1.0 as the excess $+10 \%$ of the contract demand or over $10 \%$ contract demand. Four time-slots are highlighted, 06:3007:00, 08:15-09:45, 12:15-12:45, and 17:15-20:00. For example, during the time-slot of 09:30-09:45 (PPP), an $\mathrm{AUCR}=1.25$ determined that the microdistribution system was operating as over the contract demand, and the demand response is detailed according to the following procedure:

Step 1) give the AUCR $=1.25$ to estimate the desired DG's capacity using the Eqs. 19 and 20, and $S_{D G}=15.5 \mathrm{~kW}$,

Step 2) compute the operation states using the Eqs. 21 to $24,\left[C F_{1}, C F_{2}, C F_{3}, C F_{4}\right]=[0.6065,1.0000$, $1.0000,1.0000]$,

Step 3) compute the outcome of strategic combinations, $\mathrm{S}=\left[s_{1}, s_{2}, s_{3}, s_{4}\right]=[0.0022, \quad 1.0000, \quad 0.0022$, 1.0000], and the desired DG's dispatch can be determined using Eq. 26, $\mathrm{S}^{+}=\max [0.0044$, $2.0000]=2.0000$,

Step 4) dispatch the DG's capacities, $S_{\text {renew }}=7.75 \mathrm{~kW}$ and $S_{a c}=7.75 \mathrm{~kW}$, using the Eqs. 27 to 29 , as seen in Fig. 8c.

The simulation results from 09:00 a.m. - 10:15a.m. were also shown in Table 2. During OPP hours, 05:45 - 06:30, AUCRs have a value of less than 1.00, while the electricity demand approach that of the OPP's contract demand, as seen in Fig. 8b. For example, from 05:45a.m. - 06:00a.m., the demand response also provides an operational strategy, as $\mathrm{S}=\left[s_{1}, s_{2}, s_{3}, s_{4}\right]=[0.8352,0.9231,0.8352,0.9231]$ and $\mathrm{S}^{+}=\max [1.6704,1.8462]=1.8462$. The capacity of selected DGs can be determined as $S_{\text {renew }}=5.25 \mathrm{~kW}$ and $S_{a c}=5.25 \mathrm{~kW}$ ( $S_{a c}>$ lower capacity), and their dispatches of 96 time slots are shown in Fig. 8c.

In Fig. 8a, the blue line represents electricity demand from the main grid. The total customer consumptions are 
Fig. 8 Demand response results fro each tracking time. a Day-ahead scheduled demand and demands from the main grid and DGs, b AUCR indexes, c Ancillary power sources' dispatch
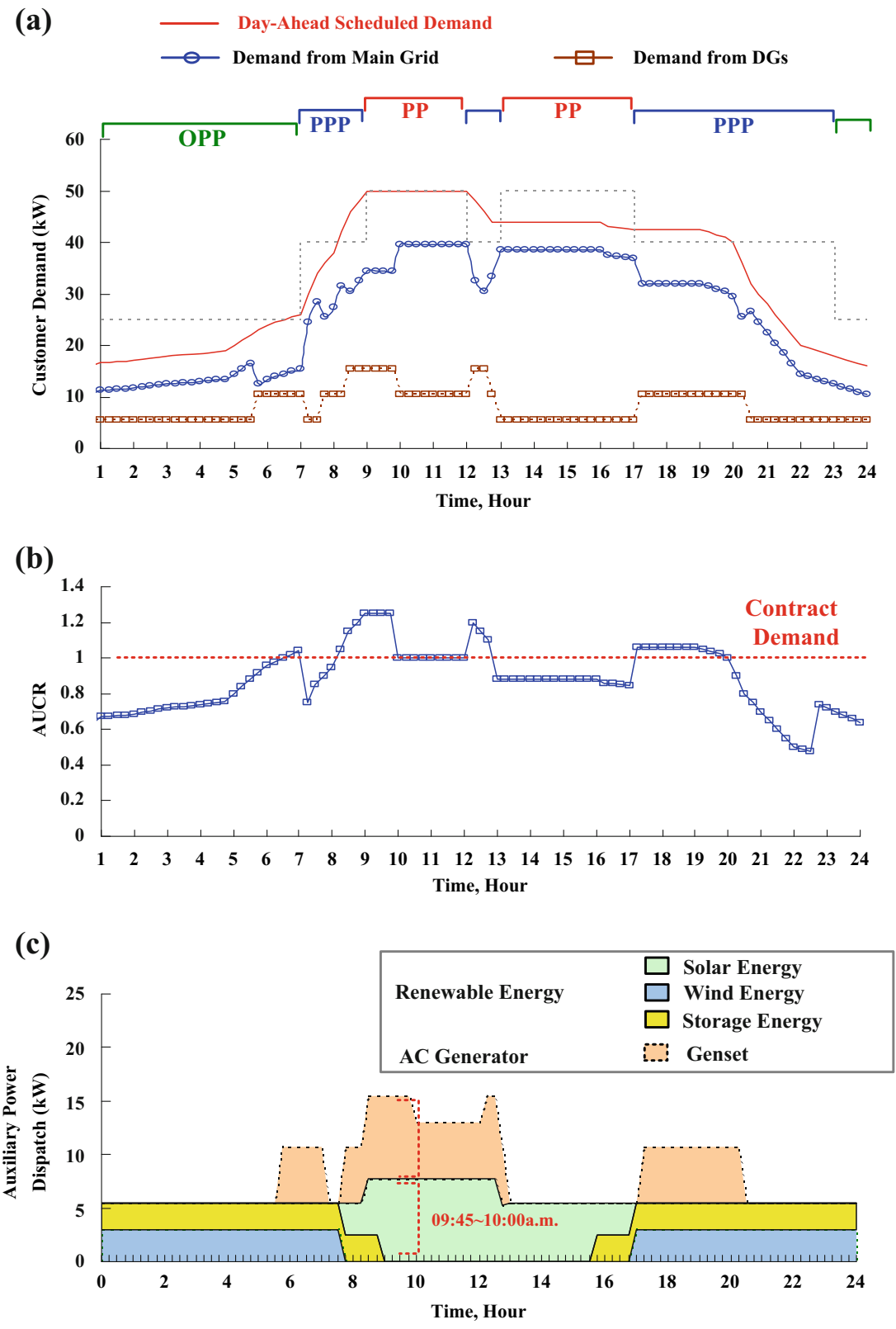

Table 2 The simulation results of demand responses and ancillary services from 05:45a.m. to 06:30a.m. and 09:00 a.m. to 10:15 p.m.

\begin{tabular}{|c|c|c|c|c|c|c|c|c|c|c|c|}
\hline \multirow{2}{*}{$\begin{array}{l}\text { Time } \\
\text { a.m. }\end{array}$} & \multirow{2}{*}{$\begin{array}{l}\text { Demand } \\
(\mathrm{kW})\end{array}$} & \multirow[t]{2}{*}{$C F_{1, h}$} & \multirow[t]{2}{*}{$C F_{2, h}$} & \multirow[t]{2}{*}{$C F_{3, h}$} & \multirow[t]{2}{*}{$C F_{4, h}$} & \multicolumn{4}{|c|}{ Dynamic Game Model (DGM) } & \multirow{2}{*}{$\begin{array}{l}\text { Renewable } \\
\text { Energy }(\mathrm{kW})\end{array}$} & \multirow{2}{*}{$\begin{array}{l}\mathrm{AC} \\
\text { Generator }(\mathrm{kW})\end{array}$} \\
\hline & & & & & & $s_{1, h}$ & $s_{3, h}$ & $s_{2, h}$ & $s_{4, h}$ & & \\
\hline 05:45 & 23.0 & 0.9802 & 0.7261 & 1.0000 & 1.0000 & 0.9802 & 0.9802 & 0.7261 & 0.7261 & 5.25 & 5.25 \\
\hline 06:00 & 24.0 & 0.8352 & 0.9231 & 1.0000 & 1.0000 & 0.8352 & 0.8352 & 0.9231 & 0.9231 & 5.25 & 5.25 \\
\hline 06:15 & 24.5 & 0.7261 & 0.9802 & 1.0000 & 1.0000 & 0.7261 & 0.7261 & 0.9801 & 0.9801 & 5.25 & 5.25 \\
\hline 06:30 & 25.0 & 0.6065 & 1.0000 & 1.0000 & 1.0000 & 0.6065 & 0.6065 & 1.0000 & 1.0000 & 5.25 & 5.25 \\
\hline 09:00 & 50.0 & 0.0022 & 1.0000 & 1.0000 & 1.0000 & 0.0022 & 0.0022 & 1.0000 & 1.0000 & 7.75 & 7.75 \\
\hline 09:15 & 50.0 & 0.0022 & 1.0000 & 1.0000 & 1.0000 & 0.0022 & 0.0022 & 1.0000 & 1.0000 & 7.75 & 7.75 \\
\hline 09:30 & 50.0 & 0.0022 & 1.0000 & 1.0000 & 1.0000 & 0.0022 & 0.0022 & 1.0000 & 1.0000 & 7.75 & 7.75 \\
\hline 09:45 & 50.0 & 0.0022 & 1.0000 & 1.0000 & 1.0000 & 0.0022 & 0.0022 & 1.0000 & 1.0000 & 7.75 & 7.75 \\
\hline 10:00 & 50.0 & 0.6065 & 1.0000 & 1.0000 & 1.0000 & 0.6065 & 0.6065 & 1.0000 & 1.0000 & 5.25 & 5.25 \\
\hline
\end{tabular}


Table 3 Benefit comparisons

\begin{tabular}{|c|c|c|c|c|c|c|c|c|}
\hline \multirow[t]{2}{*}{ Strategy } & \multicolumn{3}{|c|}{ Contract Demand (kW) } & \multirow{2}{*}{$\begin{array}{l}\text { Excess } \\
<10 \%, \\
(\mathrm{~kW})\end{array}$} & \multirow{2}{*}{$\begin{array}{l}\text { Excess } \\
>10 \%, \\
(\mathrm{~kW})\end{array}$} & \multicolumn{3}{|c|}{ Billing Charge, \$ } \\
\hline & Time & $S$ & $\Delta S$ & & & Base Charge & Penalty & Sum \\
\hline \multirow[t]{4}{*}{ Day Ahead Schedule } & PP & 10 & 0 & 0.0 & 0.0 & $2,362.0$ & 0.0 & $2,362.0$ \\
\hline & PPP & 15 & 10 & 4.0 & 6.0 & 708.0 & 1227.2 & $1,935.2$ \\
\hline & OPP & 25 & 5 & 2.5 & 2.5 & $1,180.0$ & 590.0 & $1,770.0$ \\
\hline & Sum & 50 & 15 & 6.5 & 8.5 & $4,250.0$ & $1,817.2$ & $6,067.2$ \\
\hline \multirow[t]{4}{*}{ Demand Response } & $\mathrm{PP}$ & 10 & 0 & 0.0 & 0.0 & $2,362.0$ & 0.0 & $2,362.0$ \\
\hline & PPP & 15 & 0 & 0.0 & 0.0 & 708.0 & 0.0 & 708.0 \\
\hline & OPP & 25 & 0 & 0.0 & 0.0 & $1,180.0$ & 0.0 & $1,180.0$ \\
\hline & Sum & 50 & 0 & 0.0 & 0.0 & $4,250.0$ & 0.0 & $4,250.0$ \\
\hline
\end{tabular}

Billing charge for day-ahead: $6067.2 \$$, Penalty: $1817.2 \$$

Billing charge for demand response: $4250.0 \$$, Penalty: $0.0 \$$

Genset fuel and maintenance cost: $113.18 \$$,

$\mathrm{PF}>90 \%$, reward: $C_{S} \leq 4250.0 \$ \times 0.015 \times(0.8-0.9 \sim 0.95)=-6.375 \$ \sim-9.563 \$$,

Charge reduction: $6067.2 \$-(4250.0 \$+113.18 \$)+(-6.375 \$)=1697.65 \$$

seen to decrease from $807.10 \mathrm{kWh}$ to $613.73 \mathrm{kWh}$ per day, and the consumption charges are thus lowered for fuel generation costs. The flexibility ranges for integrating $10 \%-$ $25 \%$ of DGs were achieved. The renewable and storage energy has a priority curtailment strategy to avoid expensive energy sources. Genset fuel and maintenance costs are about $10.14 \$ / \mathrm{kWh}-15.46 \$ / \mathrm{kWh}$ at $50 \%$ to $75 \%$ of the maximum capacity. The total cost of AC ancillary power is 113.18 \$ per day, and thus when compared with the dayahead scheduled demand, the demand response can reduce billing charges $1697.65 \$$ per day in relation to the cost of electricity equipment, as seen in the benefit comparison of Table 3. In addition, the OPF was used to verify the demand response strategy in each time-slot. The PF can rise to $\geq$ $90 \%-95 \%$, with a reward of $C_{S} \leq-6.375 \$ \sim-9.563 \$$ per day. It is therefore concluded that use of the demand response will be of considerable benefit to the electricity customer.

\section{Conclusion}

This study presents the fractional-order integrator and DGM for a peak-period dynamic demand response strategy in smart grids. Based on the forecasted scheduled loads, the fractional-order integral based indicator was employed to identify customer demand quantity, and the demand response strategy was then performed in relation to dispatching ancillary power, when demands exceeded contract quantity. The DGM represented outcomes in a strategic form and determined the capacity of selected DGs. Use of the demand response can reduce $23.96 \%$ of an electricity customer's power consumption, and can also avoid a penalty charge of 1817.2\$. Although the billing charges slightly increased for genset fuel and maintenance costs, the total charge reduction can be reduced by $27.98 \%$ per day. The proposed methods can handle dynamic demand response programs to facilitate demand and dispatch DGs. In a smart grid, AMI can provide predicted usage profiles, daily usage profiles, and real time usage data. demand response aggregators and electricity customers can track power consumptions and DG information via AMI and VNM. The timing slot for demand response program can range 1 hour in an electricity market to 1 day for day-ahead forecast. In the electricity market, announcement addressed demand response schedules and DG information, thus an aggregator program carried out match the requirements according to schedule by available DGs. Therefore, DG resources were requested to be available for customers' demand during each timing slot. For these support methods, a smart grid integrating energy management, load management, and ancillary services can operate to supply electricity customers, in order to reduce dependence on the main grid. The algorithms and demand response programs are also easily to implement in an embedded system and to further integrate into the AMI/AGI. However, key policies required are to: (1) perform dynamic demand response programs using the active-duty DGs during PP hours or contract hours; (2) promote an innovating business model for energy management, load management and ancillary services as demand response aggregators and generation aggregators; (3) encourage green financial loans for constructing onsite generation and energy pools, such as rooftop photovoltaic system, small scaled co-generation plants, and 
storage devices; and (3) increase flexibility for integrating DGs and storage devices in Taiwan. Hence, the proposed model for an aggregator program is a promising solution to provide an increase of $10 \%-25 \%$ flexibility and reliability of customer dynamic demands during PP hours in the summer season.

Acknowledgments This work is supported in part by the National Chin-Yi University of Technology, Taiwan, under contract number: NCUT 15-T-CE-018, duration: September 12015 July 31 2016, and is supported in part by the Ministry of Science and Technology (MOST), Taiwan, under contract number: MOST 104-2221-E-244010, duration: August $12015 \sim$ October 312016.

\section{References}

1. Wang Z, Paranjape R, Sadanand A, Chen Z (2013) Resiential demand response: an overview of recent simulation and modeling applications, $26^{\text {th }}$ Annual IEEE Canadian Conference on Electrical and Computer Engineering, May 5-8

2. Lu N (2012) An evaluation of the HVAC load potential for providing load balancing services. IEEE Trans on Smart Grid 3(3):12631270

3. Pacific Gas and Electric Company (2013) Aggregator programs, Demand Response Fact sheet

4. Rodriguez-Molina J, Martinez-Nunez M, Martinez J-F, PerezAguiar W (2014) Business models in the smart grid: challenges, opportunities and proposals for prosumer profitability. Energies 7:6142-6171

5. Gulich O (2010) Technological and business challenges of smart grids-aggregator's role in current electricity market, Master's thesis, Lappeenranta University of Technology Faculty of Technology and Electrical Engineering

6. Anderson RN, Boulanger A, Powell WB, Scott W (2011) Adaptive stochastic control for the smart grid. Proceeding of the IEEE 99(6):1098-1115

7. Bai H, Miao S, Ran X, Ye C (2015) Optimal dispatch strategy of a virtual power plant containing battery switch stations in a unified electricity market. Energies 8:2268-2289

8. (2015). Virtual net metering policy background and tariff summary report, Center for sustainable energy, california solar energy industries, and association, interstate renewable energy council

9. Langham E, Cooper C, Ison N (2013) Virtual net metering in Australia: opportunities \& barriers Report prepared for Total Environment Centre

10. Guo Y, Pan M, Fang Y (2012) Optimal power management of residential customers in the smart grid. IEEE Trans on Parallel and Distributed Systems 23(9):1593-1606

11. Reddy KS, Madhusudan Kumar TK, Mallick H, Sharon S (2014) Lokeswaran, a review of integration, control, communication and metering of renewable energy based smart grid. Renew Sust Energ Rev 38:180-192
12. Che L, Shahidehpour M (2014) DC Microgrid: economic operation and enhancement of resilience by hierarchical control. IEEE Trans Smart Grid 5(5):2517-2526

13. Nguyen K-L, Won D-J, Ahn S-J, Chung Il-Y (2012) Power sharing method for a grid connected microgrid with multiple distributed generators. J Electr Eng Technol 17(4):459-467

14. Abegaz BW, Mahajan SM (2015) Optimal real-time integration control of a virtual power plant, 2014 North American Power Symposium, pp 1-6

15. Brusco G, Burgio A, Menniti D, Pinnarelli A, Sorrentino N (2014) Energy management for an energy district with demand response availability. IEEE Trans Smart Grid 5(5):2385-22393

16. Lin C-H, Huang C-H, Yi-Chun D, Chen J-L (2011) Maximum photovoltaic power tracking for the PV array using the fractional-order incremental conductance method. Appl Energy 88(12):4840-4847

17. Li F, Qiao W, Sun H, Wan H, Zhang P (2010) Smart transmission grid: vision and framework. IEEE Trans Smart Grid 1(2):168177

18. Sakis Meliopoulos AP, Cokkinides G, Huang R, Farantatos E, Choi S, Lee Y, Yu X (2011) Smart grid technologies for autonomous operation and control. IEEE Trans Smart Grid 2(1):1-10

19. Aalami HA, Parsa Moghaddam M, Yousefi GR (2010) Demand response modeling considing interruptible / curtaiable loads and capacity market programs. Appl Energy 87:243-250

20. Yang P, Chavali P, Gilboa E, Nehorai A (2013) Parallel load schedule optimization with renewable distributed generators in smart grids. IEEE Trans Smart Grid 4(3):1431-1441

21. Golshannavaz S, Afsharnia S, Aminifar F (2014) Smart distribution grid: optimal day-ahead scheduling with reconfigurable topology. IEEE Trans Smart Grid 5(5):2402-2411

22. Krishna BT (2011) Studies on fractional order differentiators and integrators: a survey. Signal Process 91(3):386-426

23. Petras I (2011) Fractional-order nonlinear systems: modeling, analysis and simulation, Nonlinear Physical Science, Springer, ISSN $1867-8440$

24. Jian-Xing W, Li C-M, Ho Y-R, Ming-Jui W, Huang P-T, Lin C$\mathrm{H}$ (2016) Bilateral photoplethysmography analysis for peripheral arterial stenosis screening with a fractional-order integrator and info-gap decision-making. IEEE Sensor J 16(8):2691-2700

25. Doebeli M, Hauert C (2005) Models of cooperation based on the Prisoner's Dilemma and Snowdrift game. Ecol Lett 8:748-766

26. Nowak MA (2006) Five rules for the evolution of cooperation. Science 314(8):1560-1563

27. Siemens (2010) Smart energy consumption and the smart grid. https://www.usa.siemens.com/buildingechnologies

28. Aalami HA, Parsa Moghaddam M, Yousefi GR (2010) Demand response modeling considering interruptible/curtailable loads and capacity market programs. Appl Energy 87(1):243250

29. Sofana Reka S, Ramesh V (2016) A demand response modeling for residential consumers in smart grid environment using game theory based energy scheduling algorithm Ain Shams Engineering Journal Article in Press. doi:10.1016/j.asej.2015.12.004

30. Krishna BT (2011) Studies on fractional order differentiators and integrators: a survey. Signal Process 91(3):386-426 